\title{
Facts from Faeces: Prey Remains in Wolf, Canis lupus, Faeces Revise Occurrence Records for Mammals of British Columbia's Coastal Archipelago
}

\author{
Michael H. H. Price ${ }^{1}$, Chris T. Darimont ${ }^{1,2}$, Neville N. Winchester ${ }^{1}$, and Paul C. PaqueT ${ }^{2,3}$ \\ ${ }^{1}$ Department of Biology, University of Victoria. P.O. Box 3020, Victoria, British Columbia, V8W 3N5 Canada \\ ${ }^{2}$ Raincoast Conservation Society. P.O. Box 26, Bella Bella, British Columbia V0T 1B0 Canada \\ ${ }^{3}$ Faculty of Environmental Design, University of Calgary, 2500 University Drive Northwest, Calgary, Alberta T2N 1N4 \\ Canada
}

Price, Michael H. H., Chris T. Darimont, Neville N. Winchester, and Paul C. Paquet. 2005. Facts from faeces: prey remains in Wolf, Canis lupus, faeces revise occurrence records for mammals of British Columbia's coastal archipelago. Canadian Field-Naturalist 119(2): 192-196.

Archipelagos often harbour taxa that are endemic and vulnerable to disturbance. Conservation planning and research for these areas depend fundamentally on accurate and current taxonomic inventories. Although basic ecological information is in its infancy, the temperate rainforest islands of coastal British Columbia are undergoing rapid human-caused modification, particularly logging. We report herein new mammal records for these islands as determined by prey remains in the faeces of Wolves (Canis lupus), the area's apex mammalian terrestrial predator. Of particular interest is our detection of Marten (Martes americana) on islands previously inventoried and island occupancy by Moose (Alces alces), which have apparently migrated recently to coastal British Columbia. Remains in faeces provided valuable new species occurrence information, but more extensive and focused inventories are required to generate predictions of island occupancy by mammals based on biotic and abiotic landscape features.

Key Words: Wolves, Canis lupus, conservation, distribution, faeces, inventories, islands, mammals, archipelago, British Columbia.

Oceanic archipelagos often harbour taxa that are endemic, highly vulnerable to disturbance, and prone to extinction (Burkey 1995; Alcover et al. 1998). Sensible land-use planning often is constrained by a paucity of data on the distribution and abundance of organisms (Soulé and Kohm 1989), which may be particularly severe on islands. Biotic inventories provide critical information for conservation planning but frequently are not conducted because of time, financial, or other constraints (Kremen 1994). Due to accelerating rates of habitat loss, species inventories may be the foundation by which to measure the extent of human influences on extinction-prone biotas (Cook et al. 2001). Conversely, in poorly studied systems facing imminent disturbance, inventories may instigate timely conservation strategies and identify important areas for conservation research.

The numerous islands constituting British Columbia's coastal archipelago are nearly pristine yet face increasing pressure from development, particularly logging (Darimont and Paquet 2000*, 2002). Although earlier distribution reports have been valuable (McCabe and Cowen 1945; Cowen and Guiguet 1975; Craig 1990*, Nagorsen 1990), a paucity of fundamental ecological information still remains (such as complete mammal community records) for British Columbia's islands. In contrast, mammalian distribution on the adjacent Alexander Archipelago of Southeast Alaska has been well described (MacDonald and Cook 1996) and notable patterns of biogeography (e.g., Conroy et al 1999) and endemism (e.g., Cook and MacDonald 2001; Fleming and Cook 2002; Small et al. 2003) have emerged.

Accounts of mammal occurrence on islands are not always systematic but often dynamic, reflecting iterative coalescence of various collection records, accounts, and personal observations (e.g., MacDonald and Cook 1996). We extend this process here by benefiting from the foraging habits of coastal British Columbia's apex mammalian predator, the Wolf (Canis lupus), which has a wide potential niche.

During summers 2000 and 2001, we collected Wolf faeces along British Columbia's coast between the Kshwan Valley $\left(55^{\circ} 37^{\circ} \mathrm{N}, 129^{\circ} 48^{\prime} \mathrm{W}\right)$ in the north and the Koeye River $\left(51^{\circ} 46^{\prime} \mathrm{N}, 127^{\circ} 53^{\prime} \mathrm{W}\right)$ in the south (Figure 1). Our study area and sampling procedures are well described elsewhere (Darimont and Paquet 2000*, 2002; Darimont et al. 2004). Herein we identify mammalian prey occurring in faeces collected on islands only. We compared hair in faeces with voucher samples and also used dichotomous keys (Mathiak 1938; Mayer 1952; Stains 1958; Price 2003*). We compared these records of prey remains on islands with existing information regarding mammal occurrence for the British Columbia archipelago (McCabe and Cowen 1945; Cowen and Guiguet 1975; Craig 1990*, Nagorsen 1990) and herein report differences.

Wolves may deposit faeces from prey items consumed on other landmasses, but we consider this potential bias negligible. Although not well described, esti- 


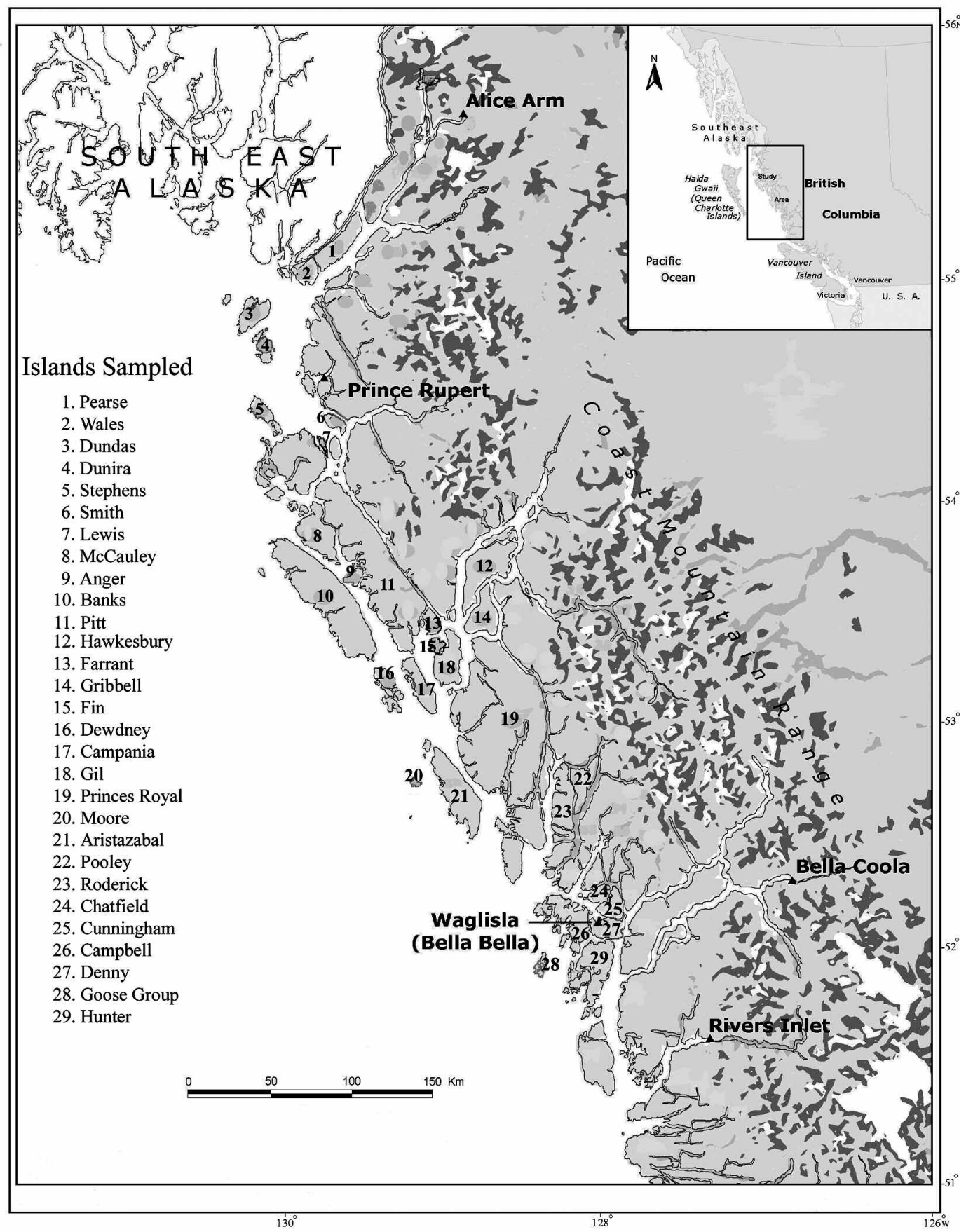

FIGURE 1. Study area and islands surveyed for mammal occurrence in British Columbia's coastal archipelago during summers 2000 and 2001

mates of typical "gastric emptying times" in wild and captive wolves are rapid, ranging from 8 to 56 hours (Floyd et al. 1978; Weaver 1993; Kreeger et al. 1997; Peterson and Cuicci 2003). Weaver (1993) noted an average of four defecations/day in wolves fed ad libi- tum. Moreover, wolves typically rest after feeding and limit travel for several days thereafter (Mech 1966; Peterson 1977; Hayes et al. 2000; Peterson and Cuicci 2003). Finally, $65 \%$ of mammals we identified on each island were found in two or more scats. 
TABLE 1. Mammal species identified in Wolf (Canis lupus) faeces collected on 29 islands in British Columbia's coastal archipelago during 2000 and 2001. Shown only are mammals not previously recorded in McCabe and Cowen (1945), Cowen and Guiguet (1975); Craig (1990*), or Nagorsen (1990). Species are as follows: Mule Deer (Odocoileus hemionus sitkensis); Pine Marten (Martes americana); Mink (Mustela vison); River Otter (Lontra canadensis); Weasel (Mustela erminea); Black Bear (Ursus americanus); Moose (Alces alces); Beaver (Castor canadensis). Sampling site codes match those in Figure 1. Islands previously inventoried for mammal occurrence indicated by asterisk.

\begin{tabular}{|c|c|c|c|c|c|c|c|c|c|}
\hline \multirow[t]{2}{*}{ Island } & \multirow{2}{*}{$\begin{array}{l}\text { Area } \\
\left(\mathrm{km}^{2}\right)\end{array}$} & \multirow[b]{2}{*}{ Deer } & \multirow[b]{2}{*}{ Marten } & \multicolumn{3}{|c|}{ Mammals Detected } & \multirow[b]{2}{*}{ B. Bear } & \multirow[b]{2}{*}{ Moose } & \multirow[b]{2}{*}{ Beaver } \\
\hline & & & & Mink & R. Otter & Weasel & & & \\
\hline 1. Pearse & 226 & $\mathrm{X}$ & $\mathrm{X}$ & & $X$ & & $\mathrm{X}$ & & \\
\hline 2. Wales & 97 & $X$ & & & & $\mathrm{X}$ & & & \\
\hline 3. Dundas & 160 & & & $\mathrm{X}$ & $X$ & $X$ & & & $\mathrm{X}$ \\
\hline 4. Dunira & 22 & & & & & $X$ & & & \\
\hline 5. Stephens & 78 & & & & & & & & \\
\hline 6. Smith & 51 & $X$ & & & & & & & \\
\hline 7. Lewis & 7 & $X$ & & & & & & & \\
\hline 8. McCauley* & 273 & & & & & & & & \\
\hline 9. Anger & 51 & $X$ & & & & & & & \\
\hline 10. Banks* & 1024 & & $X$ & & & & & & \\
\hline 11. Pitt* & 1349 & & & & & & & $\mathrm{X}$ & \\
\hline 12. Hawkesbury & 322 & $X$ & $X$ & $\mathrm{X}$ & & & $\mathrm{X}$ & & $\mathrm{X}$ \\
\hline 13. Farrant & 50 & $\mathrm{X}$ & $\mathrm{X}$ & & & & & & \\
\hline 14. Gribbell & 207 & $X$ & & & & & & & $\mathrm{X}$ \\
\hline 15. Fin & 13 & $X$ & & & & & & & \\
\hline 16. Dewdney & 37 & $X$ & & & $\mathrm{X}$ & & & & \\
\hline 17. Campania* & 157 & & & & & & & & \\
\hline 18. Gil & 238 & $\mathrm{X}$ & $X$ & $X$ & $X$ & & $X$ & & \\
\hline 19. Princess Royal* & 2295 & & $X$ & & & & & & \\
\hline 20. Moore* & 5 & & & & & & & & \\
\hline 21. Aristazabal* & 451 & & $X$ & & & & & & \\
\hline 22. Pooley & 162 & $\mathrm{X}$ & $X$ & $X$ & & $X$ & $X$ & & $X$ \\
\hline 23. Roderick & 239 & $\mathrm{X}$ & & & $\mathrm{X}$ & $\mathrm{X}$ & & & \\
\hline 24. Chatfield* & 48 & & & & & & & & \\
\hline 25. Cunningham & 115 & $\mathrm{X}$ & & & & & & & \\
\hline 26. Campbell & 145 & & & & & & & & \\
\hline 27. Denny & 127 & $X$ & $X$ & $X$ & & & & & \\
\hline 28. Goose* & 24 & $\mathrm{X}$ & & & & & & & \\
\hline 29. Hunter* & 399 & & & & & & & & \\
\hline
\end{tabular}

Early distribution reports (above) collectively inventoried 10 of 29 islands surveyed in this study. Of particular note are our new accounts for Pine Marten (Martes americana) on Banks, Princess Royal, and Aristazabal Island (Figure 1), which previous studies did not detect. MacDonald and Cook (1996) reported (non-introduced) occupancy of Marten on nine Southeast Alaskan islands, adjacent to British Columbia's coast. Conroy et al. (1999) commented on their absence there from relatively small islands $\left(<232 \mathrm{~km}^{2}\right)$. In British Columbia, we identified Marten on four islands smaller than $232 \mathrm{~km}^{2}$, including one as small as $50 \mathrm{~km}^{2}$ (Table 1). These differences, however, may reflect island isolation (i.e., distance from other landmasses). Conroy et al. (1999) found that isolation (not size) best predicts species occurrence in coastal Alaska. Finally, the distributions of animals that are trapped commercially, such as Marten, may also reflect introductions and harvest pressure.

Also notable is the presence of Moose (Alces alces) on Pitt Island. Moose have not been reported previously on islands of British Columbia and are thought to range only in localised areas of major mainland rivers and the heads of inlets (Nagorsen 1990; Shackleton 1999; Blood 2000; but see Darimont et al. 2005). Mammals documented on islands not previously surveyed included other representatives of Cervidae and Mustelidae, as well as Ursidae and Castoridae (Table 1).

Data from faeces present potential biases and opportunity. One limitation, and a function of our limited sampling and the dietary niche of Wolves, is a lack of data on other taxa (e.g., Fisher, Martes pennanti), and especially smaller rodents. The Deer Mouse (Peromyscus maniculatus), for example, was absent from our samples. This species occurs on coastal islands and has been the subject of pioneering work on insularity in the region (McCabe and Cowen 1945), and continues to be a model organism elsewhere (e.g., Vucetich et al. 2001). Our "facts from faeces" approach, however, increases the breadth of valuable information available from analysing "waste" from animals (Putman 1984; Kohn and Wayne 1997). 
New mammalian records for coastal British Columbia have scientific value and utility in conservation debate and land-use planning. As data accumulate, we hope to present a coherent explanation as to what biotic and abiotic conditions predict mammalian diversity on British Columbia's islands. Moreover, we agree wholeheartedly with MacDonald and Cook (1996) that, "the most distressing issue regarding our lack of knowledge for this vast area [coastal temperate rainforests] is that planners and policy makers are generating management decisions with great uncertainty. This is especially disconcerting given the accelerating rate of human-induced change occurring within the region's ecological systems".

\section{Acknowledgments}

This study took place in the Traditional Territories of several First Nation groups, from whom we sought permission before research began. We are extremely grateful to the Raincoast Conservation Society for financial and logistical support, field colleagues too numerous to acknowledge adequately, and skippers Stephen Anstee, Brian Falconer, Jean-Marc Leguerrier, and Dave Lutz. The McCaw Foundation, National Geographic Society, Vancouver Foundation, Wilburforce, World Wildlife Fund Canada, and private donors kindly provided funding. While preparing the manuscript, CTD was supported by a Natural Sciences and Engineering Research Council (NSERC) - Industrial Post-graduate Scholarship.

\section{Documents Cited (marked * in text)}

Craig, V. 1990. Area-distance relationships for mammals on islands of British Columbia. Independent study semester thesis. Simon Fraser University. Vancouver, British Columbia. 31 pages, plus appendices.

Darimont, C. T., and P. C. Paquet. 2000. The gray wolves of British Columbia's coastal rainforests: Findings from Year 2000 pilot study and conservation assessment. Technical Report prepared for the Raincoast Conservation Foundation. Victoria, British Columbia. 62 pages.

Price, M. H. H. 2003. Foraging ecology of wolves in British Columbia's coastal archipelago: the biogeography of predation. BSc. honours thesis. University of Victoria. Victoria, British Columbia. 52 pages.

\section{Literature Cited}

Alcover, J. A., A. Sans, and M. Palmer. 1998. The extent of extinctions of mammals on islands. Journal of Biogeography 25: 913-918.

Burkey, T. V. 1995. Extinction rates in archipelagos: implications for populations in fragmented habitats. Conservation Biology 9: 527-541.

Blood, D. 2000. Moose in British Columbia. Ecology, Conservation, and Management. British Columbia Ministry of Wildlife, Lands, and Parks. Victoria, British Columbia.

Conroy, C. J., J. R. Demboski, and J. A. Cook. 1999. Mammalian biogeography of the Alexander Archipelago of Alaska: a north temperate nested fauna. Journal of Biogeography 26: 343-352.
Cook, J. A., and S. O. MacDonald. 2001. Should endemism be the focus of conservation efforts along the North Pacific Coast of North America? Biological Conservation 97: 207-213.

Cook, J. A., A. L. Bidlack, C. J. Conroy, J. R. Demboski, M. A. Fleming, A. M. Runck, K. D. Stone, and S. O. MacDonald. 2001. A phylogeographic perspective on endemism in the Alexander Archipelago of southeast Alaska. Biological Conservation 97: 215-227.

Cowen, I. M., and C. J. Guiguet. 1975. The mammals of British Columbia. British Columbia Provincial Museum. Victoria, British Columbia.

Darimont, C. T., and P. C. Paquet. 2002. The gray wolves, Canis lupus, of British Columbia's central and north coast: distribution and conservation assessment. Canadian Field-Naturalist 116: 416-422.

Darimont, C. T. , P. C. Paquet, T. E. Reimchen, and V. Crichton. 2005. Range expansion by moose into coastal temperate rainforests of British Columbia. Diversity and Distributions 11: 235-239.

Darimont, C. T., M. H. H. Price, N. N. Winchester, J. Gordon-Walker, and P. C. Paquet. 2004. Predators in natural fragments: foraging ecology of wolves in British Columbia's Central and North Coast Archipelago. Journal of Biogeography 31: 1867-1877.

Fleming, M. A., and J. A. Cook. 2002. Phylogeography of endemic ermine (Mustela erminea) in southeast Alaska. Molecular Ecology 11: 795-807.

Floyd, T. J., L. D. Mech, and P. A. Jordan. 1978. Relating wolf scat content to prey consumed. Journal of Wildlife Management 42: 528-532.

Hayes, R. D., A. M. Baer, U. Wotschikowsky, and A. S. Harestad. 2000. Kill rate by wolves on moose in the Yukon. Canadian Journal of Zoology 78: 49-59.

Kohn, M. H., and R. K. Wayne. 1997. Facts from feces revisited. Trends in Ecology and Evolution 12: 223-227.

Kreeger, T. J., G. Delgiudice, and L. D. Mech. 1997. Effects of fasting and feeding on body composition of gray wolves (Canis lupus). Canadian Journal of Zoology 75: 1549-1552.

Kremen, C. 1994. Biological inventory using target taxa: A case study of the butterflies of Madagascar. Ecological Applications 4: 407-422.

MacDonald, S. O., and J. A. Cook. 1996. The land mammal fauna of southeast Alaska. Canadian Field-Naturalist 110: 571-598.

Mathiak, H. A. 1938. A key to hairs of the mammals of southern Michigan. Journal of Wildlife Management 2: 251-268.

Mayer, W. V. 1952. The hair of California mammals with the keys to the dorsal guard hairs of California mammals. American Midland Naturalist 38: 480-512.

McCabe, T. T., and I. M. Cowen. 1945. Peromyscus maniculatus macrorhinus and the problem of insularity. Transactions of the Royal Canadian Institute 25: 117-216.

Mech, L. D. 1966. The wolves of Isle Royale. U.S. National Park Fauna Series Number 7. Washington, D.C.

Nagorsen, D. W. 1990. The mammals of British Columbia: a taxonomic catalogue. Royal British Columbia Museum Memoir 4: 1-140.

Peterson, R. O. 1977. Wolf ecology and prey relationships on Isle Royale. United States National Park Scientific Series, Number 11, Washington, D.C. 
Peterson, R. O., and P. Ciucci. 2003. The wolf as a carnivore. Pages 104-130 in Wolves. Behaviour, ecology, and conservation. Edited by L. D. Mech and L. Boitani. University of Chicago Press, Chicago, Illinois.

Putman, R. J. 1984. Facts from faeces. Mammal Review 14: 79-97.

Shackleton, D. 1999. Royal British Columbia Museum handbook: hoofed mammals of British Columbia. Volume 3. Mammals of British Columbia. UBC Press, Vancouver, British Columbia. 268 pages.

Small, M. P., K. D. Stone, and J. A. Cook. 2003. American marten (Martes americana) in the Pacific Northwest: population differentiation across a landscape fragmented in time and space. Molecular Ecology 12: 89-103.
Soulé, M. E., and K. A. Kohm, Editors. 1989. Research priorities for conservation biology. Island Press, Washington, D.C.

Stains, H. J. 1958. Field guide to guard hair of middle western furbearers. Journal of Wildlife Management 22: 95-97.

Vucetich, L. M., J. A. Vucetich, C. P. Joshi, T. A. Waite, and R. O. Peterson. 2001. Genetic (RAPD) diversity in Peromyscus maniculatus populations in a naturally fragmented landscape. Molecular Ecology 10: 35-40.

Weaver, J. L. 1993. Refining the equation for interpreting prey occurrence in gray wolf scats. Journal of Wildlife Management 57: 534-538.

Received 12 March 2004

Accepted 14 March 2005 